\title{
Role of pharmacist in providing drug information and education for patients with chronic diseases during Transition of Care
}

\author{
Umi Athiyah, Abdul Rahem, Catur Dian Setiawan, Andi Hermansyah \\ Faculty of Pharmacy, Universitas Airlangga, Surabaya, Indonesia
}

Keywords
Chronic disease
Drug information
Patient education
Pharmacist
Transition of care
Correspondence
Abdul Rahem
Faculty of Pharmacy
Universitas Airlangga
Indonesia
abdulrahem@ff.unair.ac.id

\section{Introduction}

According to Law number 36 of 2009 on health, pharmaceutical practices that include manufacturing along with quality control of pharmaceutical preparation, security, procurement, storage and distribution of the drug, prescription-based drug service, drug information service and development of drug, medicinal ingredient and traditional medicine must be carried out by health workers who have expertise and authority in accordance with the provisions of law and regulation (Ministry of Health Indonesia, 2009). The health workers who have expertise and authority mentioned refers to the pharmacist. Management of pharmaceutical preparations in the health care system must be based on the needs and characteristics of the health service facility, which aims to minimise the cost and maximise the level of service to the community (Saha \& Ray, 2019).
Therefore, the pharmacist must always consider various characteristics of health facilities, including the culture of the people who use the health facility, both in normal condition and in the condition of the health crisis. In times of crisis, pharmacists are responsible for coordinating the supply of medicines and ensuring access to safe and quality drug supplies that are efficacious (Lemtiri et al., 2020), with an amount that matches the needs of the health service facility.

Pharmacy, as one of the practice places for pharmacists, also becomes a strategic health facility as a partner for medical personnel or other health facilities to prepare drugs in that place. Therefore, it is necessary to have good cooperation between pharmacist in the pharmacy with other health workers in the hospital or other health facilities, especially in the time of health crisis. Hence, this strong relationship will be able to solve problems related 
to optimal management of health products which is the main challenge during a health crisis such as a pandemic (Lemtiri et al., 2020). All pharmacies and supply chain leaders must have a strategy to address shortages and ensure an adequate supply of all drugs used, especially those used for a lifetime treatment by patients (Badreldin et al., 2020).

In addition to the management aspects as mentioned above, another responsibility of pharmacist in pharmacy is clinical pharmacy service as stated in the regulation of the Minister of Health of the Republic of Indonesia number 73 of 2014 on the standard of pharmaceutical service in pharmacy (Ministry of Health Indonesia, 2016). Through the clinical pharmacy service, a pharmacist in pharmacy must also ensure the success of patient therapy with roles such as disease prevention and infection control, adequate storage and supply of drugs, patient care, and support for health workers. The main responsibility of a pharmacist is to provide drug information to the health professional as well as to counsel patients (Visacri, Figueiredo, \& Lima, 2020). The knowledge and understanding of the role of a clinical pharmacist by doctors need to be improved to build effective collaboration between pharmacists and other health workers. Therefore, it is necessary to advocate health service providers and stakeholders about the role of clinical pharmacy service in providing drug therapy management (Alhossan \& Alazba, 2019).

Over the past few years, the pharmacist's role has evolved from a provider of the drug to a provider of service and information, and finally to a provider of patient care by actively participating in the treatment process. The pharmacist's next task is to ensure that the patient's drug therapy is indicated properly, is available most effectively, is the safest, and is comfortable for the patient (Merks et al., 2020). Thus, in fact, there are many roles of pharmacist in the aspect of clinical pharmacy service that can be done in order to increase the success of therapy, such as, a pharmacist can ensure that interaction between drugs occurs through prescription study, especially for a patient who gets a lot of drugs such as a psychiatric patient. In particular, prescription for a patient receiving multiple drugs needs to be thoroughly verified and examined, and pharmacists dispensing these drugs must ensure that drug interaction does not exist (AIRuthia et al., 2019).

Pharmacist in pharmacy is at the forefront of improving patient health, identifying treatment-related problems, and being involved in a decision about medication (Costantino, 2020). Several studies have shown that pharmacist intervention in a patient with chronic kidney disease leads to decreased Drug Related Problems (DRPs), polypharmacy, improved anaemia management, blood pressure, and quality of life (van Berlo-van de Laar et al., 2020). Most of the drug-related problems are substantially reduced (Liu et al., 2020) with the involvement of community pharmacist in the treatment of the patient with chronic disease, in which this is also part of the pharmacist's role. The involvement of pharmacists in the community in diabetes mellitus service management programs is seen to be very beneficial by the program manager and the patient (Thakur et al., 2020). Therefore, to maintain health, this group of vulnerable patients is highly dependent on the expanding role of the community pharmacist in the management of chronic disease (Okoro, 2020).

Intervention by pharmacists in long-term care improves treatment outcomes by increasing medication suitability, reducing drug amounts, and leading to lower treatment costs (Sadowski et al., 2019). A prospective study conducted by Chiarelli et al. (2020) related to the evaluation based on the integrated expertise of pharmacist and doctor confirms that drug-related problem often occurs in multi-comorbid elderly patients who are hospitalised so that integrated collaboration between pharmacist and doctor is needed in the process of optimising treatment (Chiarelli et al., 2020). The proportion of claims associated with administering the wrong drug and administering the wrong dose has decreased, indicating that pharmacists and medical personnel have made an improvement to reduce this type of medication error through various technological development efforts (Reiner, Pierce, \& Flynn, 2020). Empirical data from several studies in community pharmacy show that medication management by a pharmacist leads to the identification of many Drug Therapy Problems (DTP) and positive responses from various parties to pharmacists for their success in solving DTP. Even when no DTP is identified, the patient still benefits from counselling and education during a visit to a community pharmacy (Salmasi et al., 2020).

Counselling, information, and education (CIE) by a pharmacist in community pharmacy is needed, considering that the success of therapy, especially in chronic disease patients, is largely determined by patient adherence to medication and drug use. Low adherence to treatment and lack of knowledge about the disease are the main factors for treatment failure (Chandrasekhar et al., 2020). Providing information done by pharmacists can improve patient understanding of the disease and its treatment (Hutami \& Rokhman, 2013), which is expected to affect the outcome of therapy for the patient.

So far, research data related to CIE by a pharmacist in community pharmacy are general. This means that the data are obtained based on all characteristics of patients who come to the pharmacy. For the benefits of CIE for a patient suffering from chronic disease for participants of the Social Security Agency (BPJS), specifically for contribution assistance participants (PBI) at a returnreferral pharmacy, namely pharmacy that collaborates 
with BPJS to serve return-referred patients, there has not been much research done. $\mathrm{PBI}$ patients are poor and incapable patients who previously do not adhere to the treatment due to constraints on cost. Since the enactment of the National Health Insurance, which is managed by BPJS, they have received contribution assistance from the government so that they can run free medical treatment at health service facilities in collaboration with BPJS and can also get free medicine from pharmacies that work with BPJS. Since they rarely do medication and rarely come to the pharmacy, this group of patients is unlikely to be exposed to such information by a pharmacist in the pharmacy. Thus, this research aims to "Investigate the impact of a pharmacist providing drug information and education for a discharged patient with chronic disease".

\section{Methods}

\section{Study design}

This study used a cross-sectional observational design, as the respondents were patients with chronic diseases, especially diabetes mellitus and hypertension, who obtained drugs at five independent pharmacies serving return-referral patients categorised as PBI participants in BPJS in East Java with the following inclusion criteria:

1. Patients with diabetes mellitus or hypertension;

2. Took medicine from July to October 2019;

3. Able to read and write;

4. Able to speak Bahasa Indonesia;

5. Willing to be research respondents;

6. Categorised as PBI participants in BPJS.

Ethics approval was not deemed necessary as the survey population did not include any-risk groups, and anonymity was assured to all participants. In addition, signed informed consent was obtained from all participants prior to data collection.

\section{Sample}

The sample size was 153 patients, the sample size ( $n$ ) was calculated using the simple random sampling formula with notation $\mathrm{N}$ (total population size), $\mathrm{P}$ (population proportion), and $\mathrm{d}$ (degree of error) as shown below (Ogston et al., 1991):

$$
\operatorname{Vâr}(\hat{P})=\frac{P(1-P)}{n} \times \frac{N-n}{N-1} .
$$

$\mathrm{Z}=1.96, \mathrm{P}=0.5, \mathrm{~d}=0.05, \mathrm{~N}=252$ people with diabetes, so $n=152.42=153$ respondents

The sampling technique was purposive sampling.

\section{Research variables}

The variables were the type of information provided by the pharmacist to the patient, the patient's understanding of the condition and the patient's adherence to consuming the drug. In addition, the independent variable was the patient's understanding, while the dependent variable was the patient's adherence to consuming the drug.

\section{Research instrument}

The instrument used in this study was a questionnaire. Before being used, the questionnaire was first tested for its validity and empirical reliability. Then the result of the questionnaire trial was analysed with statistics to determine the validity and reliability of the instrument. The instrument was declared valid if the correlation coefficient was $>0.3$ and reliable if the Alpha Cronbach value was $>0.6$ ( Priyastama, 2017). The results of the reliability and validity tests showed that the instrument was valid with a correlation value greater than 0.3 , namely from the nine statement items. The lowest correlation value was 0.421 , and the highest was 0.844 , with an Alpha Cronbach value of 0.822 .

\section{Data analysis}

To determine the effect of respondent understanding on medication adherence, statistical analysis was performed using chi-square.

\section{Results}

In this study, the gender of the respondents showed that the majority was women, with $72.5 \%$, as shown in Table I. The majority of respondents' ages ranged from 41 - 50 years old with $37.9 \%, 51$ - 60 years old with $26.8 \%$, and above 60 years old with 29.4\%, as presented in Table I. As seen, the patients of chronic diseases range from a very productive age, even starting at the age of under 40 years.

\section{Table I: Characteristics of respondents}

\begin{tabular}{lll}
\hline Characteristics & $\begin{array}{l}\text { Frequency } \\
\text { (n: 153) }\end{array}$ & Percentage (\%) \\
\hline Gender & 111 & \\
Female & 42 & 72.5 \\
Male & & 27.5 \\
Age (years) & 9 & \\
$\leq 40$ & 58 & 5.9 \\
$41-50$ & 41 & 37.9 \\
$51-60$ & 45 & 26.8 \\
$>60$ & & 29.4 \\
\hline Smoking habit & 137 & \\
Not smoking & 16 & 89.5 \\
Smoking & & 10.5 \\
Comorbidity & 110 & 71.9 \\
Diabetes mellitus & 43 & 28.1 \\
Hypertension & & \\
\hline
\end{tabular}


In this study, there were several materials that were asked of respondents regarding the information provided by the pharmacist to the patient when taking drugs at the pharmacy. Table II showed that of the six information provided by the pharmacist to the patient, based on the respondent's answer to the questionnaire given, the most frequent information related to how to use the drug was $83 \%$ of respondents answered always. Next was information related to the importance of adherence in using the drug to control the illness, which was $71.9 \%$.

Table II: Opinions of respondents related to information provided by the pharmacist at the pharmacy

\begin{tabular}{|c|c|c|c|}
\hline \multirow[t]{2}{*}{ Statements } & \multicolumn{3}{|c|}{ Respondents' answers (\%) } \\
\hline & $\begin{array}{c}\text { Never } \\
\text { n (\%) }\end{array}$ & $\begin{array}{c}\text { Occasionally } \\
\text { n (\%) }\end{array}$ & $\begin{array}{c}\text { Always } \\
\text { n (\%) }\end{array}$ \\
\hline $\begin{array}{l}\text { The pharmacist explains } \\
\text { the right place to find } \\
\text { safe, qualified, and } \\
\text { efficacious medicine }\end{array}$ & $\begin{array}{c}99 \\
(64.7)\end{array}$ & $52(34)$ & $2(1.3)$ \\
\hline $\begin{array}{l}\text { The pharmacist explains } \\
\text { how to use the drugs in } \\
\text { each drug given to you }\end{array}$ & $0(0)$ & $26(17)$ & $\begin{array}{l}127 \\
(83)\end{array}$ \\
\hline $\begin{array}{l}\text { The pharmacist explains } \\
\text { how and where to store } \\
\text { drug in your home }\end{array}$ & $\begin{array}{c}13 \\
(8.5)\end{array}$ & $68(44.4)$ & $\begin{array}{l}72 \\
(47.1)\end{array}$ \\
\hline $\begin{array}{l}\text { The pharmacist explains } \\
\text { how to destroy/dispose } \\
\text { of the drug if there is a } \\
\text { broken or expired drug at } \\
\text { home }\end{array}$ & $\begin{array}{c}63 \\
(41.2)\end{array}$ & $72(47)$ & $\begin{array}{c}18 \\
(11.8)\end{array}$ \\
\hline $\begin{array}{l}\text { The pharmacist explains } \\
\text { that your illness requires } \\
\text { long-term treatment }\end{array}$ & $7(4.6)$ & $51(33.3)$ & $\begin{array}{c}95 \\
(62.1)\end{array}$ \\
\hline $\begin{array}{l}\text { The pharmacist explains } \\
\text { the importance of } \\
\text { adherence in using drugs } \\
\text { to control the disease } \\
\text { you are suffering from }\end{array}$ & $2(1.3)$ & $41(26.8)$ & $\begin{array}{c}110 \\
(71.9)\end{array}$ \\
\hline
\end{tabular}

Respondents' understanding of all information conveyed by pharmacists, and specifically related to understanding the need for long-term treatment for the diseases they suffer from, the majority of respondents said they understood, with the percentage of $70 \%$ respectively as shown in Table III. Respondents adherence to using drugs after getting information from pharmacists increased; this was indicated by the respondent recognition of the questionnaire answers in using drugs; $68 \%$ answered obediently.
Table III: Respondents' understanding and adherence in using drugs

\begin{tabular}{lcc}
\hline \multicolumn{1}{c}{ Question } & \multicolumn{2}{c}{ Respondents' answers } \\
& No, $\mathbf{n}(\%)$ & Yes, $\mathbf{n}(\%)$ \\
\hline $\begin{array}{l}\text { Do you understand } \\
\text { everything the pharmacist } \\
\text { explains? }\end{array}$ & $46(30)$ & $107(70)$ \\
\hline $\begin{array}{l}\text { Do you understand that your } \\
\text { illness requires long-term } \\
\text { treatment? }\end{array}$ & $46(30)$ & $107(70)$ \\
\hline $\begin{array}{l}\text { Are you obedient in using the } \\
\text { medicine after getting } \\
\text { information from the } \\
\text { pharmacist? }\end{array}$ & $49(32)$ & $104(68)$ \\
\hline
\end{tabular}

\section{Discussion}

The result of this study should be a concern, especially for health workers, to always provide education and counselling to the community so that they can live a healthy lifestyle, given that as the main factor in the occurrence of chronic diseases such as diabetes mellitus and hypertension and cardiovascular is a lifestyle (Cokro et al., 2018).

Several other similar studies also have similarities related to age range, as in research conducted by Alghamdi and the authors (2017). This is probably because women are usually more diligent in carrying out a health check at health care facilities both to the public health centre and to the hospital so that more women were chosen as respondents. This study is in accordance with several previous studies that stated that the majority of patients with chronic disease, especially diabetes mellitus (DM), are women, as in the study of Silarova and the authors (2018) and research by Moawad and the authors (2014).

The majority of hypertensive patients are also women, according to the research result of Athiyah and the authors (2019). Smoking is a risk factor for health problems in the community because it is associated with the incidence of several diseases, including hypertension (Sohn, 2018). In several studies, it has been shown that smoking will increase the incidence of stroke in hypertensive patients (Safiri \& Ayubi, 2017). In addition, smoking is also a cause of failure to control blood sugar for DM patients and also contributes to the initial incidence of DM-related complications in addition to the direct toxic effects of smoking (Gerber et al., 2013). The results of this study indicated that the majority of respondents did not smoke, with $89.5 \%$ as in Table I. This was because the majority of respondents studied were women. It is generally known that usually women do not like smoking (Athiyah et al., 2019). If we look at the number of male respondents and respondents who smoked in Table I, it showed that not all male respondents smoked because the number of 
smokers was only 16 respondents while the number of male respondents was 42 people.

Meanwhile, at least the information provided by the pharmacist was related to the right place to get safe, quality, and efficacious drugs. This condition occurs because pharmacists think that the success of therapy is greatly influenced by adherence and the correct use of drugs (Rahem et al., 2019) so that the informational pressure point is directed at the correct use of the drug by the pharmacist. In addition, the failure of therapy and the emergence of side effects of treatment in a patient with chronic diseases such as diabetes mellitus and hypertension is because patients often forget to take medication (Stanton-Robinson et al., 2018), so that pharmacist considers this information as a part that must always be conveyed to the patient to improve therapy outcomes. While related to the information where the place to get the medicine is safe, qualified, and efficacious, perhaps the pharmacist thinks it is not too principle because this patient is a BPJS participant with the PBI category, which is believed by their pharmacist to take the drug at the pharmacy because in the pharmacy they get the medicine for free.

To determine the effect of understanding medication adherence, chi-square statistical analysis was performed. The results of statistical analysis showed that the value of $p=0.0001$, meaning that the respondents' understanding of how to use the drug had a significant effect on medication compliance. This study is in accordance with the results of research by Rahem and the authors (2019) and Stanton-Robinson and the authors (2018), which present that information affects understanding and subsequently affects adherence to drug use. As previously explained that medication adherence has the potential to increase the success of therapy, so providing information by the pharmacist in this study has a great opportunity to control blood sugar in people with diabetes and control blood pressure in people with hypertension. This study is also in accordance with the results of research by Suradnyana and the authors (2018), which state that the provision of education has an effect on the knowledge of patients with diabetes and affects adherence to drug use.

\section{Conclusions}

Pharmacist is at a unique position in the transitions of care. Pharmacists can provide information and education that may contribute to improving patient's understanding and adherence.
The community pharmacist is the last health worker a patient sees because, after that, the patient goes straight home. For this reason, patients' understanding regarding treatment information becomes very critical. Therefore, it is advisable for all pharmacists in community pharmacies to always provide education and information to patients who come to the pharmacy.

\section{References}

Alghamdi, M.A., Shihab, T.A., Hilabi, M.A., Alqaaiyan, S.A., Alzain, W.I., Alhumaidan, A.M., Alfageeh, K.K.A. (2017). Compliance of Type 2 Diabetic Patients to Its Management: A Cross-Sectional Survey, 3(1), 146-152. https://doi.org/10.21276/ijmrp.2017.3.1.028

Alhossan, A., \& Alazba, A. (2019). Barriers interfering with establishment of Collaborative Drug Therapy Management (CDTM) agreements between clinical pharmacists and physicians. Saudi Pharmaceutical Journal, 27(5), 713-716. https://doi.org/10.1016/j.jsps.2019.04.006

AlRuthia, Y., Alkofide, H., Alosaimi, F. D., Sales, I., Alnasser, A., Aldahash, A., Almutairi L,. AlHusayni, M.M., Alanazi, M.A. (2019). Drug-drug interactions and pharmacists' interventions among psychiatric patients in outpatient clinics of a teaching hospital in Saudi Arabia. Saudi Pharmaceutical Journal, 27(6), 798-802. https://doi.org/10.1016/j.jsps.2019.05.001

Athiyah, U., Rahem, A., \& Setiawan, C.D. (2019). The Influence of Participation of the Social Security Agency (BPJS) Health on Therapeutic Success in Hypertension Patients at Community Health Centers. Research Journal of Pharmacy and Technology, 12(1), 93-98. https://doi.org/10.5958/0974360x.2019.00018.0

Badreldin, H.A., Raslan, S., Almudaiheem, H., Alomari, B., Almowaina, S., Joharji, H., Alawagi, M., Al-jedai, A. (2020). Pharmacists roles and responsibilities during epidemics and pandemics in Saudi Arabia: An opinion paper from the Saudi Society of clinical pharmacy. Saudi Pharmaceutical Journal, 28(8), 10301034. https://doi.org/10.1016/j.jsps.2020.07.002

Chandrasekhar, D., Mohanlal, S.P., Mathew, A.C., \& Muhammed Hashik, P.K. (2020). Impact of clinical pharmacist managed patient counselling on the knowledge and adherence to antiepileptic drug therapy. Clinical Epidemiology and Global Health, 8(4), 1242-1247. https://doi.org/10.1016/j.cegh.2020.04.021

Chiarelli, M.T., Antoniazzi, S., Cortesi, L., Pasina, L., Novella, A., Venturini, F., Nobili, A., Mannucci, P.M., R. (2020). Pharmacist-driven medication recognition/ reconciliation in older medical patients. European Journal of Internal Medicine, (March), 1-6. https://doi.org/10.1016/j.ejim.2020.07.011

Cokro, F., Rahem, A., Aditama, L., \& Kristianto, F.C. (2018). The Impacts of Lifestyle Modification Education towards Cardiovascular Risk Profile. Indonesian Journal of Clinical Pharmacy, 7(3), 154-161. https://doi.org/10.15416/ijcp.2018.7.3.154

Costantino, R.C. (2020). The U.S. medicine chest: Understanding the U.S. pharmaceutical supply chain and the role of the pharmacist. Journal of the American Pharmacists (7) 1-6. https://doi.org/10.1016/j.japh.2020.07.018

Gerber, P.A., Locher, R., Schmid, B., Spinas, G.A., \& Lehmann, R. (2013). Smoking is associated with impaired long-term 
glucose metabolism in patients with type 1 diabetes mellitus. Nutrition, Metabolism and Cardiovascular Diseases, 23(2), 102-108. https://doi.org/10.1016/j.numecd.2011.08.007

Hutami, S.T., \& Rokhman, M.R. (2013). Consumer Perception and Expectation of Community Pharmacist. Jurnal Farmasi Klinik Indonesia, 2(3), 85-93.

Ministry of Health Indonesia (2016). Presidential Decree No. 73 of 2016 about standard of pharmacy practice in community pharmacy.

Ministry of Health Indonesia (2009). National Health Law No. 36 of 2009.

Lemtiri, J., Matusik, E., Cousein, E., Lambiotte, F., \& Elbeki, N. (2020). Les missions du pharmacien clinicien en soins critiques pendant la pandémie COVID-19. Annales Pharmaceutiques Françaises, 1-5. https://doi.org/10.1016/j.pharma.2020.09.001

Liu, J., Wang, C., Chen, X., Luo, J., Xie, J., Li, S., Hu, J., Shi, C. (2020). Evaluation of pharmacist interventions as part of a multidisciplinary cancer pain management team in a Chinese academic medical center. Journal of the American Pharmacists Association, 60(1), 7680. https://doi.org/10.1016/j.japh.2019.09.005

Merks, P., Jakubowska, M., Drelich, E., Świeczkowski, D., Bogusz, J., Bilmin, K., Sola, K.F., May, A., Majchrowska, A., Koziol, M., Pawlikowski, J., Jaguszewski, M., Vaillancourt, R. (2020). The legal extension of the role of pharmacists in light of the COVID-19 global pandemic. Research in Social and Administrative Pharmacy, (May), 1-6. https://doi.org/10.1016/j.sapharm.2020.05.033

Moawad, S. (2014). Assessment of Knowledge among Saudi Diabetic Children/ Adolescent at Riyadh City. American Journal of Nursing Science, 3(1), 5. https://doi.org/10.11648/j.ajns.20140301.12

Ogston, S.A., Lemeshow, S., Hosmer, D.W., Klar, J., \& Lwanga, S.K. (1991). Adequacy of Sample Size in Health Studies. Biometrics, 47(1), 347. https://doi.org/10.2307/2532527

Okoro, R.N. (2020). COVID-19 pandemic: The role of community pharmacists in chronic kidney disease management supportive care. Research in Social and Administrative Pharmacy, 15-18. https://doi.org/10.1016/j.sapharm.2020.07.008

Priyastama, R. (2017). Buku sakti kuasai SPSS pengolahan data \& analisis data (smart book for learning SPSS). Yogyakarta: Start Up.

Rahem, A., Utami, W., Sukorini, A.I., \& Effendi, M.H. (2019). The Effect of Advocacy on Understanding, and Levels of Blood Glucose in Diabetes Mellitus Patients, Asian Journal of Pharmaceutics 13(4), $375-380$

Reiner, G., Pierce, S.L., \& Flynn, J. (2020). Wrong drug and wrong dose dispensing errors identified in pharmacist professional liability claims. Journal of the American Pharmacists Association, 60(5), e50e56. https://doi.org/10.1016/j.japh.2020.02.027

Sadowski, C.A., Charrois, T.L., Sehn, E., Chatterley, T., \& Kim, S. (2019). Journal of the American Pharmacists Association The role and impact of the pharmacist in long-term care settings: A systematic review. Journal of the American Pharmacists Association. 1-9. https://doi.org/10.1016/j.japh.2019.11.014

Safiri, S., \& Ayubi, E. (2017). Smoking, Hypertension, and Their Combined Effect on Ischemic Stroke Incidence: A Prospective Study among Inner Mongolians in China: Methodological and Statistical Issues. Journal of Stroke and Cerebrovascular Diseases, 26(12), 3033. https://doi.org/10.1016/j.jstrokecerebrovasdis.2017.09.022

Saha, E., \& Ray, P.K. (2019). Modelling and analysis of inventory management systems in healthcare: A review and reflections. Computers and Industrial Engineering, 137(September), https://doi.org/10.1016/j.cie.2019.106051

Salmasi, S., Tsao, N.W., Li, K., Shaske, J.N., Marra, C.A., \& Lynd, L.D. (2020). Characterization of pharmacist-based medication management services in a community pharmacy. Research in Social and Administrative Pharmacy, 16(2), 178182. https://doi.org/10.1016/j.sapharm.2019.04.051

Silarova, B., Douglas, F.E., Usher-Smith, J.A., Godino, J.G., \& Griffin, S.J. (2018). Risk accuracy of type 2 diabetes in middle aged adults: Associations with sociodemographic, clinical, psychological and behavioural factors. Patient Education and Counseling, 101(1), 4351. https://doi.org/10.1016/j.pec.2017.07.023

Sohn, K. (2018). Relationship of Smoking to Hypertension in a Developing Country. Global Heart, 13(4), 285-292. https://doi.org/10.1016/j.gheart.2018.01.004

Stanton-Robinson, C., Al-Jumaili, A.A., Jackson, A., Catney, C., Veach, S., \& Witry, M.J. (2018). Evaluation of community pharmacist-provided telephone interventions to improve adherence to hypertension and diabetes medications. Journal of the American Pharmacists Association, 58(4), S120-S124. https://doi.org/10.1016/j.japh.2018.04.030

Suradnyana, I.G.M., Rahem, A., Aditama, L., Farmasi, F., \& Surabaya, U. (2018). Effect of Patient Decision Aid on Level of Knowledge, Attitude, Practice and Clinical Outcome of Type 2 Diabetes , $7(2) . \quad 89 \quad-\quad 98$. https://doi.org/10.15416/ijcp.2018.7.2.89

Thakur, T., Galt, K.A., Siracuse, M.V., Fuji, K.T., \& Bramble, J. D. (2020). National survey of diabetes self-management program coordinators views about pharmacists' roles in diabetes education. Journal of the American Pharmacists Association, 60(2), 336-343.e1. https://doi.org/10.1016/j.japh.2019.10.009

van Berlo-van de Laar, I.R.F., Sluiter, H.E., Riet, E. van 't, Taxis, K., \& Jansman, F.G.A. (2020). Pharmacist-led medication reviews in pre-dialysis and dialysis patients. Research in Social and Administrative Pharmacy, (February), 1-6. https://doi.org/10.1016/j.sapharm.2020.02.006

Visacri, M.B., Figueiredo, I.V., \& Lima, T. de M. (2020). Role of pharmacist during the COVID-19 pandemic: A scoping review. Research in Social and Administrative Pharmacy, (July). 2-8 https://doi.org/10.1016/j.sapharm.2020.07.003 